This item was submitted to Loughborough's Research Repository by the author.

Items in Figshare are protected by copyright, with all rights reserved, unless otherwise indicated.

\title{
Youth sport volunteering: developing social capital?
}

\section{PLEASE CITE THE PUBLISHED VERSION}

http://dx.doi.org/10.1080/13573320802615288

\section{PUBLISHER}

(C) Routledge (Taylor \& Francis group)

\section{VERSION}

AM (Accepted Manuscript)

\section{PUBLISHER STATEMENT}

This work is made available according to the conditions of the Creative Commons Attribution-NonCommercialNoDerivatives 4.0 International (CC BY-NC-ND 4.0) licence. Full details of this licence are available at: https://creativecommons.org/licenses/by-nc-nd/4.0/

\section{LICENCE}

CC BY-NC-ND 4.0

\section{REPOSITORY RECORD}

Kay, Tess, and Steven Bradbury. 2019. "Youth Sport Volunteering: Developing Social Capital?”. figshare. https://hdl.handle.net/2134/24539. 
Title:

Youth sport volunteering: developing social capital?

Date of submission:

29 J une 2007

Date of revised submission: $11^{\text {th }}$ October 2007 
Youth sport volunteering: developing social capital?

\begin{abstract}
This paper analyses the capacity of youth sport volunteering to contribute to the development of social capital. Following a review of the emergence of social capital as a key theme in UK sport policy, the paper focuses on the ability of a structured sports volunteering programme to equip young people with skills for effective volunteering, and provide opportunities for 'social connectedness' through sports volunteer placements. The study uses survey data $(n=160)$ and qualitative interviews $(n=10)$ with young people to examine how the national Step into Sport programme impacts on participants' personal and skill development, and on their commitment to community involvement. Interviews with education and sport professionals $(n=33)$ provide additional expert perspectives on the programme's impact on participants. Both sets of respondents report strong individual benefits to participants from their involvement, and increased social connectedness in a range of contexts. The paper concludes by considering the implications of the study for claims about the potential contribution of sport to social capital.
\end{abstract}

KEYWORDS: SPORT, VOLUNTEERING, SOCIAL CAPITAL, CITIZENSHIP 


\section{Youth sport volunteering: developing social capital?}

\section{Introduction}

In this paper, we address aspects of the debate about whether and how sport may contribute to social outcomes for young people. Complementing Misener and Mason's (2006) recent critique of the social impact of sporting events, our investigation is into the capacity of sports involvement to contribute to the development of social capital. The focus is upon youth sport volunteering, which appears to 'tick the boxes' of a number of topical UK policy agendas: in particular, it provides a form of 'social participation' or 'civic engagement' that can foster connectedness between young people and their fellow citizens, empower them as resourceful individuals, engage them with their communities and thus potentially contribute to the development of citizenship and social capital. These concepts are however much disputed and the debate surrounding the associated policy agendas is intense. Here we analyse the extent to which young people's experiences of volunteering in sport may match or fall short of the policy expectations that surround them.

In our analysis we firstly examine this policy context, the concepts that are used within it, the extent to which sport may theoretically contribute to the associated policy aims, and the literature pertaining to young people's involvement in volunteering. The paper next draws on a mixed-methods study with youth sport volunteers to examine their experiences of sports volunteering. The concluding discussion considers to what extent the study provides evidence that social capital can be generated through participation in sports volunteering. 


\section{Sport in the pursuit of social capital}

The British tradition of using sport to pursue social policy goals has been greatly heightened since the first New Labour government specifically incorporated sport in its ambitious cross-cutting policy to combat social exclusion. Since then a range of national and local initiatives have emerged that seek to use sport to engage hard-toreach young people and address some of the relational dimensions of exclusion, poverty and inequality.

The use of sports-based interventions to improve the lives of young people reflects assumptions about the potential social benefits of sport. Sport has been described as an important mechanism for reducing criminality, engaging the disaffected, encouraging educational attainment and hence increasing employment opportunities. There is however little evidence that these outcomes necessarily occur and even less that they can be causally attributed to sport, and a number of critiques (e.g. Blackshaw \& Long 2005, Coalter 2007) have concluded that the research base is unsatisfactory. While some sports-based interventions achieve many positive results, it is also apparent that the impact is variable at a number of levels: sport itself is a diverse product, it is more attractive to some groups than others, individuals' responses to sport vary, and responses are also affected by the structural characteristics of sports projects (Coalter, Allison, \& Taylor, 2002; Long et al, 2002) Nonetheless, theoretical analyses of sport continue to be supportive of its potential to engage young people and, on balance, there is a broad belief that sport may have the potential to offer social benefits (e.g., Collins, Henry, Houlihan \& Buller, 1999) but for whom, on what scale, in what circumstances and to what effect is uncertain? 


\section{Social capital, social participation and active citizenship}

In this paper we join the debate about the social outcomes of sport by considering the extent to which a programme that trains and develops youth sports volunteers may contribute to the development of social capital. 'Social capital' is a concept that has become increasingly popular in UK policy making circles in recent years as a result of its perceived capacity to contribute to greater social cohesion and civic renewal (Policy Action Team 10, 1999; Cantle, 2001; Harper, 2001). This popularity has fuelled an increasing academic debate in economics, political science and sociology (e.g. Fukuyami, 1995; Putnam, 1993 1995, 2000; Coleman, 1990, 1994; Bourdieu, 1984, 1999), and in sport and leisure studies (e.g., Blackshaw \& Long, 2005; Coalter, 2007). A range of competing definitions of social capital has inevitably emerged, prompting confusion over the concept itself and about the way in which it impacts on social relations and civil society.

The most popularly utilised academic conceptualisation of social capital has been Putnam's $(1995,2000)$ definition of it as 'networks, norms and trust that enable participants to act together more effectively to pursue shared objectives' (p. \#). Putnam argues that increased social connectedness encourages greater social solidarity and social cohesion through 'bonding' and 'bridging' individuals into a larger collective whole. Broadly speaking, bonding capital refers to the value assigned to social networks between homogenous groups of people where ties, interaction and familiarity are relatively strong. In contrast, bridging capital refers to social networks between socially heterogeneous groups of people where social ties and bonds may be looser and more diverse. From this perspective, social capital is conceptualised as a collective property rooted in reciprocity and the establishment of a range of formal and informal social networks. Whilst other analysts have argued that social capital is also premised on rational individual action (Coleman, 1990, 1994; Bourdieu, 
1984, 1986), there has been considerable support for Putnam's view of social capital underpinning a more productive, supportive, trusting and effective society to the benefit of the wider population.

Although Putnam recognises the potential for a 'dark side' to social capital, his central thesis is that social capital is a force for individual and collective good. Other writers have been more critical, highlighting the processes of exclusion that can inhibit engagement in wider civic society amongst some groups (Portes \& Landolt, 1996; Blackshaw \& Long, 2005). For example, Putnam's conceptualisation of 'bonding' social capital can lead to the exclusion of outsiders across a range of group settings, potentially sustaining patterns of racism, sectarianism, xenophobia, sexism and homophobia and the closed hegemonic structures within which such attitudes and behaviours flourish. Blackshaw and Long (2005) argue that Bourdieu's (1996) use of the theoretical concepts of field, habitus and capital therefore offers a more sensitive approach to understanding of the way in which social, cultural and economic capital synthesise the relationship between individual and society. Bourdieu (1986), like Putnam, is interested in structural determinants and social connections, but also offers a strong account of individual agency and the implications for the way in which social capital can be acquired through "profits of membership' (p. 27) and civic associations at an individual level by those with the material and symbolic resources to do so.

It is nonetheless the more structural functionalist approach to social capital put forward by Putnam which has found most favour in policy-making circles. The Organisation for Economic Co-operation and Development (OECD) has closely followed Putnam in defining social capital as 'networks together with shared norms, values and understandings that facilitate co-operation within or among groups' (Cote \& Healy, 2001: 41), in this way recognising social capital as a multi-dimensional 
concept which is located within relational networks of sociability and civil society. In the UK, the appeal of social capital has stemmed from its linkages with policy concerns around the relational aspects of social exclusion, civil renewal and individual and collective citizenship. A number of UK government departments have therefore sought to come to a consensus around the measurement and application of social capital in a policy context (Babb, 2005), with the Office for National Statistics (Whiting \& Harper, 2003) identifying five key indicators: social participation, civic participation, social networks and social support, reciprocity and trust and views of the local area. These indicators feature both objective and subjective dimensions, ascertain individual attitudinal and behavioural processes and evaluate levels of engagement with wider community networks. It is in the context of these conceptualisations that we are interested in exploring the potential role of (sports) volunteering to contribute to the development of social capital, through its opportunities for young people to be involved in their communities in the service of others.

In focusing on individuals' engagement with their communities, the UK's 'social capital' policy discourses frequently converge with those of the 'active citizenship' agenda that has been evident in post-1997 government responses to youth alienation and disaffection. This has resulted in a range of policy directives and initiatives designed to encourage greater levels of civic engagement and social participation amongst young people (Armstrong, 2002; Catan, 2002; Department for Education \& Skills, 2003; National Centre for Social Research, 2000). Policies include the introduction of a core 'citizenship' curriculum delivered to all young people from pre-school age to beyond compulsory education (3-18), addressing the three themes of social and moral responsibility, political literacy, and community involvement. The concept of 'community involvement' clearly overlaps with elements 
of social capital, especially those concerning social participation, social networks and support, and reciprocity.

In this context, volunteering has been seen as a key element of strategies to promote social participation and increase individual and collective citizenship, especially among young people (Social Exclusion Unit, 1998; Home Office, 1999; Home Office Citizenship Survey, 2001, 2003, 2005). National survey data on volunteering in the UK reveal a complex picture of the rates and frequency of youth volunteering (Lynn \& Davis-Smith, 1992, Davis-Smith, 1998; Attwood, Singh, Prime, \& Creasey, 2001; Kitchen, Michaelson, Wood, \& John, 2005; Munton \& Zurawan, 2003). Research indicates a sharp decline in rates of youth volunteering throughout the 1990s, from $55 \%$ of $16-24$ year-olds which had volunteered formally at least once in the previous 12 months in 1991 to $43 \%$ in 1997 and $40 \%$ in 2001 . Rates of formal volunteering of this kind increased significantly for $16-19$ year-olds from 41\% in 2003 to 53\% in 2005 but remained fairly constant amongst 20-24 year-olds between 2003 (43\%) and 2005 (42\%). These national volunteering survey findings indicate this recent upturn has meant that rates of formal youth volunteering are now broadly comparable to older, middle aged, cohorts of adult volunteers; but, also, that there is a marked drop-off rate in levels of formal volunteering across the transition from youth to adulthood.

Youth volunteering has nonetheless gained prominence as a policy mechanism for addressing concerns about young people's individual and collective citizenship. The most conspicuous example of this approach has been Millennium Volunteers (MV) programme, launched in 1999 to promote sustained volunteering amongst young adults aged 16-24. The MV programme was often targeted at socially excluded and 'at risk' young people and contributed to a marked increase in the 12-month rate of formal volunteering among $16-19$ year-olds in the early $21^{\text {st }}$ century. 
Davis-Smith, Ellis, \& Howlett's (2002) evaluation of the Millennium Volunteers initiative provides considerable support for the idea that youth volunteering can enable young people to become active members of local communities and show increased citizenship. It also found that young people's volunteer activity increased the capacity of service providers to the benefit of user groups, helped improve the wider social and physical environment of communities, contributed to improvements in inter-generational relations, and contributed to increased social capital. The successes of the MV programme have since been developed through the Russell Commission's 2005 recommendations for national strategies to recruit, retain and manage young volunteers and to legitimise the ethos of youth volunteering across a range of educational and community sector organisations (Russell, 2005). Building on this, in spring 2006, the UK government helped launch 'V-inspired', an independent charity aimed to work with and build on the existing voluntary sector infrastructure to promote and create volunteering opportunities for more than one million young people.

The provision of structured volunteering experiences for young people therefore appears to have the potential to contribute to the social participation that underpins social capital. Volunteering in sport would appear to have much to offer in this respect, with national data (Lynn \& Davis-Smith, 1992; Davis-Smith, 1998) showing that across all age groups, sport is the most popular single area for volunteer activity in the UK, cited by the $26 \%$ of all volunteers surveyed. The in-depth study of sports volunteering conducted by the Leisure Industries Research Centre (2003) confirmed that young people play a prominent role in this activity, with the 16-24 year-old age group providing $28 \%$ of all sports volunteers.

While sports volunteering yields many benefits for individuals and substantial gains for communities, its special value in relation to the social capital thesis is that it 
explicitly engages young people with their wider community. Sports volunteering therefore appears to offer a particularly appropriate form of sports involvement for achieving developing social participation by young people. In this study we examine the extent to which this appears to occur, drawing on the varied conceptualisations of social capital considered above to focus on two broad dimensions:

- The capacity of sports volunteering to foster appropriate personal and skill development for individuals. The development of these skills is a prerequisite for individuals to act as effective, active citizens who are involved in their local communities ${ }^{1}$.

- The capacity of sports volunteering to contribute to the development of social connectedness: while definitions and concepts of social capital vary, 'it is interconnectedness that is most commonly taken as the starting point for promoting shared values and generating trust that will encourage the reciprocity essential to a productive society' (Long, 2007: 2). The opportunities that sports volunteering offers for interaction with others are central to its potential contribution to social capital.

\section{The study}

\section{The project}

This study takes the form of secondary analysis of data collected through the monitoring and evaluation programme for the Step into Sport Volunteer Training

\footnotetext{
${ }^{1}$ The link between individual development and social participation is referred to in policy discourses surrounding social capital and active citizenship: for example, the UK YMCA describes youth citizenship as seeking '...to empower young people with the skills, knowledge and confidence to take charge of their lives' as a precursor to being 'active, responsible citizens' (YCare (YMCA) UK website, October 2006).
} 
Programme. Phase One (2002-2004) of the SIS project was funded by the Department for Culture, Media and Sport (DCMS) and the Home Office 'Active Communities' Unit and Phase Two (2004-2006) of the SIS project by the Department for Culture, Media and Sport (DCMS) alone. Step into Sport is managed and coordinated by Sport England, the Youth Sport Trust and Sports Leaders UK (formerly the British Sports Trust), building on the skills and expertise of these organisations' work in this important area.

Step into Sport (SIS) offers a framework of structured opportunities for young people to participate in volunteering and leadership training in sports. It aims to establish a clear pathway to progression designed to empower of participants with knowledge and experience to make a positive voluntary contribution to local sporting communities. The project has two key components. Firstly, it offers five programmes for young people aged 14-19 years, providing progressive training and experience in sports leadership and volunteering: Sport Education, Level One Sports Leadership, Top Link, Level Two Community Sports Leadership, and Community Volunteering. The programmes are facilitated by PE Teachers in schools within the national school sports partnership framework with the support of the Youth Sports Trust and Sports Leaders UK. Secondly, the project involves the development of capacity building networks involving school sports partnerships, local authorities, county sports partnerships, national governing bodies of sports and Sport England, to help strengthen local sports infrastructure and provide high quality volunteer placement opportunities for young volunteers.

\section{Methods}

The Institute of Youth Sport at Loughborough University have been responsible for monitoring and evaluating the Step into Sport project since 2002. This paper reports on qualitative research conducted during 2004-06 into the Community Volunteers 
element of the programme. 'Community Volunteers' (CV) involves young people aged 16+; it first trains young people in sports leadership, and then provides placements for sports volunteering. It thus addresses both personal and skill development, and provides opportunities for social connectedness in a distinctly sports environment. Young people attend a CV four-day training camp and/or one of a several CV one-day camps held at a range of venues nationally, and are then encouraged to complete up to 200 hours of 'Community Volunteering' in local sporting environments.

The research draws on data collected between November 2005 and June 2006. Research with the Community Volunteers themselves comprised an initial selfcompletion 'tracking survey' of 160 volunteers who had first engaged with the CV programme by attending a training camp in March and April 2003, and a subsequent set of 10 in-depth interviews with a sub-group of these respondents. Research with the three groups of stakeholders took the form of semi-structured interviews, all conducted by the same researcher. The stakeholder interviews were conducted with a representative from each of the 8 School Sports Partnerships (SSPs) who had a remit for work around the CV element of the SIS project; 10 Volunteer Co-ordinators with key responsibility for School/Clubs links at ten Sports Clubs within the same SSPS; and 15 PE staff at 15 secondary schools engaged in the delivery of the school-based stages of the SIS project, including the CV programme. The use of multiple sources allowed triangulation of views on the impact of sports volunteering on the young people and confronts to some extent criticisms of the subjectivity of qualitative data and fears of its reliability.

\section{Results}

The data are first presented for the Community Volunteers and then for the stakeholders, i.e. the interviewees from school sports partnerships and community sports clubs. 


\section{Community Volunteers}

The survey of Community Volunteers sought wide-ranging information on the young people's socio-demographic and educational background, and their experiences of sport, volunteering, the Community Volunteering programme and the Step into Sport project overall. Here we concentrate on the data relating to the impact of the experience of the volunteer placement on the young people.

160 young people responded to the tracking survey, a response rate of $26 \%{ }^{2}$. Most respondents were female (65\%), White British (92\%), and from relatively affluent 'middle income' geographical locales. Relatively few $(<12 \%)$ respondents were from the $20 \%$ of wards classed as the most deprived nationally (ONS: 2004). There were few respondents from BME communities $(n=13 ; 8 \%)$, and very few with self-reported physical disabilities, learning difficulties or a sensory impairment $(n=3,2 \%)$. In these respects the Community Volunteering respondents reflects the overall profile of participants in the Step into Sport programme. Community Volunteers (CV) is aimed at young people $16+$, and all respondents were aged between 17-20 year-olds at the time of the survey.

During their CV placements, respondents had undertaken volunteering at a range of venues, including schools (71\%), sports clubs (53\%), sports and leisure facilities (15\%) and youth clubs (12\%). Almost half (48\%) had undertaken volunteer placements at just one venue, and the remainder at two or more. Most respondents (78\%) had volunteered in more than one sport, and most (56\%) had also taken on

\footnotetext{
${ }^{2}$ The response rate was affected by changes in the circumstances of the young people who were aged 17-20 at the time of the survey. Many had left their parental home and entered work or further/higher education and were no longer contactable at their original address. In addition, we assume that as is usual with self-completion surveys, there is a level of selectivity among respondents, with those most interested and satisfied with their experiences of Community Volunteering being most likely to respond. We acknowledge this likely bias towards 'favourable' respondents and address the implications of this for the findings in the later discussion section of the paper.
} 
more than one type of volunteer function. The majority of respondents (94\%) had undertaken sports leadership and/or coaching activities; almost three-quarters (73\%) had officiated games and tournaments; and smaller numbers had undertaken administrative support (20\%), sports maintenance (15\%), information technology (5\%) or more general support (5\%) activities. Respondents had worked with a range of client groups, including primary school children (82\%), secondary school pupils (72\%), people with learning difficulties (36\%), physical disabilities $(21 \%)$ or sensory impairments (8\%), BME groups (18\%), socially excluded groups (15\%) young adults (26\%), older adults (14\%), and elderly groups (6\%).

Respondents varied in the extent of their volunteering as measured by recorded hours of voluntary activity. More than one-quarter (29\%) completed 200 hours of volunteering (SiS 'Gold Certificate'), around one-third (34\%) more than 100 hours of volunteering (Silver Certificate), 18\% more than 50 hours of volunteering (Bronze Certificate) and $19 \%$ fewer than 50 hours of volunteering. The mean number of volunteering hours undertaken as part of the CV programme was 113, with individual respondents ranging from 7 hours to over 200 .

Respondents reported a wide range of impacts from their experience of their Community Volunteers placement(s). Benefits in personal skill development were most widely reported. A large majority of respondents reported impacts such as improvements in leadership skills (88\%), communication skills (80\%) and organisational skills (65\%). Many also reported increased confidence (85\%) as a result of undertaking their $\mathrm{CV}$ placement.

Table 1 about here 
There were a number of indications that the greatest benefits were obtained by those who undertook most volunteering, and/or volunteered in diverse contexts. The respondents who were most likely to report personal development improvements were those who had volunteered for more than 100 hours, and/or done so at more than one venue, and/or undertaken a variety of volunteer activities. There were some gendered differences in response: for example, males were more likely than females to report improved organisational skills, and females were more likely than males to report improved leadership skills.

The CV placement experience had encouraged many respondents $(60 \%)$ to think about being further involved in sport and more than one-third (36\%) wanted to do further volunteering in sports. A similar proportion (35\%) wanted to obtain other sports leadership/volunteering awards as a result of their experience of doing CV 'hours'. Such aspirations were most common among those who had achieved high hours of volunteering and had diverse experiences, especially if this had involved volunteering at a local sports club or a sports and leisure facility rather than in school settings.

The CV placement experience also had a broader impact on many respondents' (49\%) interest in doing volunteer work with children and young people. There was also evidence that undertaking the placement had widened many participants' perspectives on a range of social issues, including almost one-half (49\%) who felt that they now thought more about different social groups in their community. Many interviewees expressed strong altruistic views towards volunteering and contributing to their community:

I think respect and confidence are important contributions to life and through volunteering and community work we can all help (Female, age 17) 
I think volunteering is of utmost importance in your community and you can learn more about yourself and influence the lives of others. (Male, age 17)

Volunteering has helped me to learn and gain new skills. I have been able to use these skills to help others to develop their own abilities. (Male, age 18)

Volunteering is a very worthwhile and rewarding activity. I see it as an opportunity to use my knowledge and skills to help others. (Female, age 17)

Although I could have been earning money by working in a paid job, I still felt very satisfied helping people and the community, It also felt good working together in a group to achieve something positive. (Male, age 17)

I feel that volunteering is the ultimate in self-less acts and person that takes part should be commended. My father once told me 'If you don't need help, help some-one who does. (Male, 17)

The findings from the CV survey provided substantial evidence that volunteers obtained considerable benefits from their placement experience, and that many also developed a stronger orientation to active involvement in their community. Following the analysis of the survey data, 10 in-depth interviews were conducted to obtain more detailed explanations about how undertaking placements affected the volunteers in these ways. A sample of survey respondents was selected that provided a mix of male and female volunteers, from white and BME groups, and with varying levels of Community Volunteering experience as measured in total hours undertaken.

The interviews sought information on a range of topics relating to respondents' educational and employment background and experiences of sport, of volunteering and the Step into Sport programme. Here we again concentrate on data relating specifically to the Community Volunteer placement. This falls into two broad categories: evidence of personal skill development that allowed young people to become effective volunteers and evidence of an increased orientation to the altruistic dimensions of volunteering (i.e., giving to others and contributing to community). 
In line with the survey findings, personal skill benefits were widely reported by interviewees. Many examples were given of how the experience of delivering sport opportunities through the CV placement had provided the opportunity for this development:

I think I am more organised now, because I learnt that if you haven't organised everything that you are going to do from the start then it's not going to work because the kids know that you are not prepared to do it so they just mess about. If you come prepared the kids are willing to learn. I have learnt that for myself. (Male, age 20)

My confidence has gone up loads and loads. I used to be really nervous about planning a session and now it just seems like nothing. I don't get nervous at all anymore and I'm not worried about speaking in front of big groups of people, I just get on with it now whereas before I wouldn't even speak in front of 2 people! (Female, age 20)

I used to do all the coaching techniques, all the coaching points that were part of the lesson plan, making sure the whole session goes smoothly. Making sure every aspect of the coaching was covered. I looked into coaching manuals and the internet and that gave me a different aspect on how coaches around the world teach sport. It really did open my eyes, how to teach things effectively and the kids really did follow it. It was brilliant. It really did help me. (Male, age 20)

For many interviewees, an important part of this development came from their progression during the placement, from an initial role as a helper/supporter role to one in which they had sole responsibility for aspects of organisation of the session.

In terms of after school clubs we had to put out a letter to the parents of the children who wanted to do the stuff and make sure that we got their permission and tell them how long it would be. We also had to do risk assessments as well and the mentor would help me but as time went on and I grew in confidence I would do them myself and check the sports hall and outside areas as well. I would also get all the equipment out and basically get it all organised. (Male, age 20)

In several cases volunteers progressed to lead the session themselves:

I started off in the corner and for the first couple of weeks I just helped put the mats out and the equipment and I wasn't really sure what to do because everyone else around me seemed so confident. But at the end after a bit of encouragement I was leading the warm-ups and we had a [sic] massive games at the end, like an obstacle course thing, which I led on the last session. With everyone's support it just made me grow in confidence throughout the volunteering. (Female, age 20) 
I was built-in to the lessons gradually, so at first I would just take a warm up at the beginning of the session and eventually I was taking the whole session and doing my own thing. (Male, age 20)

The placement experience made a significant impact on many volunteers' attitudes toward working with young people:

I felt a great sense of achievement, especially with younger children as I saw myself as a role model. (Female, age 18)

Some friends thought I was silly doing it for free but they didn't realise the amount of fun and satisfaction I got out of seeing the children learn new things. (Female, age 20)

To introduce new sports and techniques to the kids was brilliant because you are giving them a positive experience on different sports and hopefully they are still doing them now. (Male, age 20)

You get to know the children and their strengths and weakness and who needs help and who doesn't, [you learn that] if someone keeps doing something wrong you don't keep picking on them because they probably can't actually physically do it, so you learn things about individuals, about children. (Female, age 20)

Some of the strongest impacts arose when volunteers had the opportunity to work with youngsters with disabilities:

I really enjoyed working with children and that's what I'm doing now as a career. It showed me just how diverse children were and I really enjoyed it, especially working with the disabled children. It was amazing and is something that I would like to get into in my teaching. (Female, age 20)

In one class, one child had a mental condition and we had to adapt the session. We did Gymnastics and ... he was really excited and wanted to do it, he had a carer with him who helped him and he really enjoyed it. The carer said it was the first time anyone had involved him, which was a really good feeling. I spoke to his mother and she said how much he had enjoyed it and how much he would like to do it again, so we did some more sessions right up until the end of the summer term. (Male, age 20)

One respondent summarised the all-round individual and community benefits she had experienced through her placement:

I really enjoyed volunteering at my placement, as there was such a variety in abilities, attitudes and activities. I was forever kept on my toes and always learning something new. My leadership skills and confidence have grown enormously in all areas and not just in the sporting environment. Step into Sport has given me the chance to grow as an individual whilst doing something good for the community. (Female, age 20) 


\section{Summary}

Research with the young Community Volunteers provided extensive evidence of skill development, a pre-requisite for effective volunteering. It also yielded considerable evidence of positive experiences in engaging with others and becoming more community-oriented. Across all types of placement, young people identified learning and attitudinal shifts arising from the process of engaging directly with others and offering their skills in their service.

\section{Research with Step into Sport stakeholders}

There was strong consistency among stakeholders in their views of the impact of the CV placement experience on young people. All agreed that the experience provided increased skills and personal development for the volunteers and made a contribution to community. The latter included the practical increase in provision that the volunteers facilitated and the greater connectedness and involvement with others that this entailed.

\section{Stakeholder views of personal benefits to volunteers}

All groups of stakeholders reported that the placement experience improved personal and professional development skills amongst volunteers, including increased confidence, motivation, communication and organisational skills.

They come out with a lot of social skills and people management skills. (Club Interviewee) 
Some commented on how these benefits in turn contributed to improved social awareness and relationships:

Organisational and leadership skills have improved, motivational skills have also improved and also an awareness of their surroundings. (School interviewee)

I think the CV programme has developed the confidence of the young people tremendously. You can see them grow in terms of their own feelings of self worth. They then tend to get involved in things around the school because of their involvement with this programme. (SSCO Interviewee)

It increases their confidence and self esteem. They become more knowledgeable and confident in their own sports. It increases respect and standing amongst staff. Its been very successful in terms of head-teachers, sixth form managers and post-16 co-ordinators and all have said... the CV has had a great impact on the students'. (SSCO interviewee)

Several interviewees identified improvements in behaviour and discipline as key benefits for pupils, often leading to a general improvement in interaction and communication amongst pupils and between pupils and teachers. Some also commented on the capacity of the $\mathrm{CV}$ programme to re-engage pupils with poor behaviour records, offering detailed case-study accounts of how involvement in the volunteering programme had engaged difficult and disaffected pupils where other means had failed:

The ones who are a bit 'lively' are actually the ones that do well sometimes, because it gives them a focus. There's a lad at the moment who's got a history of problems at school throughout the school but he's absolutely leading the way in our sports leadership through Judo. He represented the school at the British Championships last week and he won a silver medal so he's really embraced it. Someone who had huge behavioural problems and who has actually become engaged by delivering sports leadership. (Sports College interviewee)

There's a lad in Year 11 who's close to permanent exclusion and he's going out every Thursday to a junior school because that's what he's into. He makes his own way down there with the other students. Normally he wouldn't cross the road to help anybody but he gets down there and helps the kids out because that's where he sees his strengths and personally gets something out of it. (School Interviewee)

The evidence provided by stakeholders closely matched volunteers' own accounts of the personal and skill development the young people had obtained through their 
volunteer placements. As the next section shows, stakeholders also offered similar views when community benefits were considered.

\section{Stakeholder views of community benefits}

Stakeholders, with their considerable experience of the sport environment, were well positioned to comment on the community dimension of the volunteer placements.

A number of representatives from School Sports Partnerships described a noticeable increased sense of citizenship amongst students in terms of improved interaction and a more positive contribution to school-life and extra-curricular activities. This was particularly evident at one Sports College where the ongoing voluntary efforts of students had contributed greatly to the provision of disability sport. In similar vein, several PE staff felt pupils had assumed much greater responsibility for their immediate sports environment, developing a fuller appreciation of sports organisation and management. Some PE staff reported that participation in student-led sports leadership/volunteering programmes had notably increased some pupils' intention to volunteer, especially to support extra-curricular activities at local primary schools.

There's a lot more to coaching than just physically working with kids. It's also about keeping registers, monitoring things, rules and regulations, child protection. That's something we tell them about. There's a lot of placements that you can do around the back-room stuff as well. We advertise that to the kids as well. They do help us and come to the sports centre and file envelopes and help with administration, making posters, etc. (PDM interviewee)

I think being involved in the Community Volunteering programme engages the pupils more with the teachers. It gets the teachers talking more to pupils than if they were just teaching them and elicits a more positive and communicative response from the pupils. (Director of Sport interviewee)

It has improved their interaction with other people within the school and it's definitely made a huge impact with our community links with other people. (SSCo interviewee) 
We've had more pupils running their own after-schools clubs with some staff monitoring and volunteers. Not just for our pupils but pupils in local primary schools. (SSCo interviewee)

It has increased pupils' intentions to do volunteering. The first year we tried to do Community Volunteering we had one person who wanted to do it and now we've got 25 pupils and we could have got 25 more. (SSCO interviewee)

Club representatives provided an insight into contributions to other elements of the sports structure and commented on the direct impact that the volunteers had had on the provision of opportunities. The presence of volunteers had enabled the increased delivery of coaching activities with key target groups of younger children. For two 'school-based' Sports Clubs, the volunteers proved invaluable in this respect:

We have had help with basketball festivals which have been arranged with the primary schools and, initially, if it hadn't been for the volunteers, we wouldn't have had the help required to make these festivals run smoothly. The volunteers have been a tremendous help in that. (Club Interviewee)

Without them I can't see how it would have been achieved. It's had a real measurable impact. Over the last two years they have impacted on hundreds of kids. Without them the 'after-schools' clubs really couldn't have existed. (Club Interviewee)

At one Sports Club it was felt that the increased coaching capacity provided by volunteers would contribute to ongoing club development:

I think that what will happen in the future is that it will help us to develop a club at a quicker speed that we may have done if the [SIS] volunteers were not there. Once they are in a position to be confident enough and have coaching qualifications they will be able to undertake some roles on a more permanent basis. (Club Interviewee)

The presence of volunteers had also enabled some Sports Clubs to deliver more focused and personalised coaching provision to client groups of younger children.

It gives us extra coaches. There's normally two adults, but if we have 2 or 3 volunteers then that's 4 or 5 coaches so it increases the supervision we can give to the kids. (Club Interviewee)

It frees the coaches up to do things that they might otherwise rush to do. They can spilt the group more and concentrate on different things they need to work on. If there's an injury they don't have to stop the session. They can sort out the injury while the session carries on. (Club Interviewee) 
The capacity of volunteers to act as role models to younger children and to assume a 'generational bridge' between younger children and older coaches was seen as a positive outcome at two Sports Clubs:

It's good to see the 7 and 8 year olds looking up to the 16 year olds and thinking this is my mentor. [It's] like a role model, really. The younger kids relate to them better. It links together the age groups very well and they look after one another. (Club Interviewee)

The kids can relate better to an 18 year old than an older coach. It also gives a youthful impression to the parents when they bring their kids along. There's [sic] a couple of young lads here who started at 7 or 8 years old and have gone all the way through, played all the way through and are now coaching. (Club Interviewee)

Volunteers were also felt to have impacted on the generational culture and helped maintain a positive sense of youthful vibrancy across the coaching and committee structures of the institution.

They have a big impact on the existing club members because they bring in new ideas, fresh abilities and a totally different outlook. (Club Interviewee)

In similar vein, PE staff at SSPs reported on feedback from local sports clubs about the positive contribution of students to local sporting communities. This was particularly apparent at clubs which had junior sections for younger children for which students' skills and experience were most relevant. At one club, which had recruited large numbers of volunteers, there was strong sense that this had helped the club 'connect' better with local schools and with the wider community.

It has helped open the club up and makes it more a part of the community. It's been reported in the press and I think it generally raises awareness of what's going at the club. Its not just about football, there are other issues with the work that's going on with schools. I think its certainly improved the status as a community club. (Club Interviewee)

\section{Summary}


The research with Step into Sport stakeholders in clubs and School Sports Partnerships provided valuable additional data on Community Volunteers' placement experiences. Stakeholders both confirmed the accounts given by the young people, and offered additional perspectives. They were more likely than the young people to identify a collective impact on broader social relationships in the school context, including those among pupils, and between pupils and teachers. Stakeholders also drew attention to the positive impact of the placements on some of their more 'difficult' or disengaged pupils whose accounts were otherwise missing from the data obtained from the CV respondents. The stakeholder data therefore have value in bringing an extra dimension to the more individualised accounts obtained from the volunteers themselves.

\section{Conclusions}

In this paper we sat out to examine whether young people's involvement in a structured programme of sports volunteering empowered young people with skills, knowledge, experiences and commitment that appeared likely to contribute to the building of social capital. We did so in the context of the general prominence of social capital as a focus in UK social policy and the wide-ranging deployment of sport to contribute to this and other social outcomes.

Our first consideration was whether the volunteering programme gave young people the opportunity for the personal and skill development that would allow them to better actively engage with their communities. In this sense we were concerned to consider the extent to which sports volunteering contributed to the development of human capital (e.g. transferable social skills and increased sense of self-worth) amongst young people. Not only did both sets of respondents identify this occurring, but they 
also explained the process through which such benefits had accrued. Several examples were given of how particular tasks produced specific benefits: for example, the experience of planning activity sessions led to improved organisational skills, and the experience of leading sports sessions resulted in increased confidence in interacting with people. These accounts of causality explicitly identified how experiences of sports volunteering engendered a positive attitudinal and behavioural impact amongst young people.

Our second concern was with the extent to which undertaking a volunteer placement facilitated 'social connectedness', both by providing opportunities for young people to engage with others in their communities, and by fostering a greater awareness of the needs of others and the positive experience to be gained from interacting with them. It was certainly the case that volunteer placements engendered increased interaction between young volunteers and a range of 'others' (young children, other pupils, teachers, club workers etc) in a largely productive capacity. Quantitative and qualitative responses also indicate that this increased interaction contributed to a greater sense of altruism and citizenship amongst young people and helped maintain and extend sports provision within local sporting infrastructures. The increased social connectedness brought about by volunteer placements was also effective in facilitating 'bonding' and 'bridging' social capital: teaching staff reported that young people interacted more with their own peers than previously, and young people themselves spoke of the benefits and satisfaction from helping others in their community. These forms of capital formation were rarely singularly manifest or mutually exclusive, but, rather, were subject to a range of competing identity constructions and the contextual framework in which volunteering took place. For example, the majority of volunteer placements took place in geographically local sports venues or in schools where young volunteers were already involved as players or pupils and which provided a relatively familiar (and more sustainable) 
sporting environment in which to volunteer. However, within these apparently limited social networks, young volunteers were simultaneously likely to be involved in coaching, officiating and more general sports leadership activities with a relatively diffuse network of younger children, and, in many cases, with disabled groups, under the tutelage of older teachers, coaches or sports development professionals. In this respect, the sites and activities for sports volunteering and the social connections engendered through this process contributed to the maintenance of 'bonding' capital and the emergence of newer forms of 'bridging' capital within particular social milieu.

In relation to both delivering volunteering opportunities, and contributing to the wider development of social connectedness, the Step into Sport Community Volunteers programme therefore appeared to achieve considerable success. In drawing conclusions from this research study, we can identify a number of core operating principles that underpinned the programme and may offer guidance for other similar initiatives:

1. The opportunity to participate in the Step into Sport programme provided a stimulus for sports volunteering: while some participants had previous experience of volunteering, many did not. This suggests that a latent demand for sports volunteering may be present in young people that can be activated through appropriate interventions.

2. The programme provided training to equip young people with the skills to perform their roles as volunteers, and through this also instilled in them with the initial confidence to do so. Young people therefore felt prepared for their volunteering experience. 
3. The CV programme provided structured opportunities for volunteering. This was a less intimidating way for young people to acquire this experience than through ad hoc approaches of their own.

4. It is important to also acknowledge that young people were partly attracted to the programme because the training element had personal instrumental value to them as a form of accreditation that could be referred to on CVs and applications for higher education and employment. It is helpful to recognise the importance of this motivation for participating. Although'selfish' motivations may appear contrary to the spirit of volunteering, this study suggested that instrumental motives do not necessarily preclude altruistic ones, and that altruistic values may in fact be developed through the direct experience of volunteering. Programmes which offer a tangible reward of this type may have the capacity to attract more young participants including those who would not necessarily be engaged otherwise.

The programme therefore appeared to work effectively because of its holistic approach, providing support for young people from the initial stages of engaging them, continuing through the process of training them, and ultimately delivering direct experience of volunteering. We are inevitably drawn to consider how widely the benefits of social capital can be accessed through this type of sports volunteering initiative. Although stakeholders specifically described the capacity of the programmes to attract some disaffected and less engaged young people, in its early years participants from low income households, black and minority ethnic communities and people with disabilities have been under-represented in Step into Sport. These are groups whom policymakers often perceive as having some of the greatest needs for greater social cohesion and active citizenship. A schools-based 
sports leadership and volunteering project which targets young people engaged in the post-compulsory school-age education sector may have limited capacity to attract pupils disaffected from the school itself and has a limited resource pool of potential participants from black and minority ethnic communities, or from disabled groups and young people from economically disadvantaged backgrounds. This does not negate the impact that sports volunteering can have, but does point to the greater challenge of stimulating participation among groups who may have most potential to benefit form their involvement.

We have mixed conclusions. First and foremost we are persuaded that the study yielded sufficient evidence to show that for many young people, sports volunteering can 'work' as a mechanism for fostering human capital and encourage the practical and intellectual connectedness which underpins the idea of social capital. When it does, the benefits experienced are clearly identifiable and this study suggests they can be causally attributed. In this respect, we argue that sports researchers may be able to be less tentative in some of their claims about whether sport can yield social benefits: it can. Nonetheless, on the other hand, we make no claims as to the permanence of such impacts. Rather, we remain acutely aware that the capacity of youth sports volunteering to engender social capital in its various forms is shaped by a range of personal and structural factors, not least of all, the capacity of individuals to possess and utilise the material and symbolic resources to access and negotiate those social networks through which social capital might be best realised. In turn, the benefits of youth sports volunteering to social capital formation will also be informed by the capacity of social (sporting) networks to exhibit a greater egalitarianism and inclusivity in dealing with and valuing the contribution made by young people from a range of socio-economic, racialised and differently abled backgrounds. 


\section{References}

Armstrong, D. (2002) Pathways into and out of crime: risk, resilience and diversity (Economic and Social Research Council).

Attwood, C., Singh, G., Prime, D., \& Creasey, R. (2001) 2001 Home Office Citizenship Survey: people, families and communities (London: Home Office).

Babb, P. (2005) Measurement of Social capital in the UK (London, ONS).

Beck, U. (2000) The Brave new World of Work (Polity Press: New York).

Blackshaw, T., \& Long, J. (2005) What's the Big Idea? A critical exploration of the concept of social capital and its incorporation into leisure policy discourse, Leisure Studies 24, 239-258.

Bourdieu, P. (1984) Distinction: A social critique of the judgement of taste (London: RKP).

Bourdieu, P. (1986) The forms of capital: in Baron, S. Field, J. Schuller, T. (eds) Social Capital - Critical Perspectives (Oxford University Press).

Bourdieu, P. (1999) The Weight of the World: Social suffering in contemporary society (Cambridge: Polity Press).

Cantle, T. (2001) Community Cohesion: A report of the independent review team (London: Home Office).

Catan, L. (2002) Youth, Citizenship and Social Change (Economic and Social Research Council).

Coalter, F., (year) Sports Clubs, Social Capital and Social Regeneration: 'ill-defined interventions with hard to follow outcomes'?, Sport in Society, 10, 537-559.

Coalter, F., Allison, M., \& Taylor, J. (2000) The role of sport in regenerating deprived areas. SECRU. Edinburgh.

Coleman, J. (1990) Equality and Achievement in Education (Boulder: Westview press).

Coleman, J. (1994) Foundations of Social Theory (Cambridge MA: Belknap Press/Harvard University Press.

Collins, M., Henry, I.P., Houlihan, B., \& Buller, J. (1999) Research Report: Sport and Social Exclusion (Loughborough: Loughborough University)

Cote, S., \& Healy, T. (2001) The Well-Being of Nations. The role of human and social capital (Organisation for Economic Co-operation and Development, Paris).

Davis-Smith, J. (1998) The 1997 National Survey of Volunteering (London: Institute of Volunteering Research).

Davis-Smith, J., Ellis, A., \& Howlett, S. (2002) UK-Wide Evaluation of the Millennium Volunteers Programme (Institute of Volunteering Research). Department for Education and Skills, Government Green Paper (2003 Every Child matters (London: Department for Education and Skills).

Fukuyami, F. (1995) Social Capital and Civil Society, Foreign Affairs 74, 89-103.

Harper. R. (2001) Social Capital: A review of the literature (London: Social Analysis and Reporting Division, Office for National Statistics).

Home Office (1999) Voluntary and Community Sector Activities: (Policy Action Team 9: London: Home Office).

Kitchen, S., Michaelson, J., Wood, N., \& John, P. (2005) 2005 Citizenship Survey: Active Communities Topic Report (London: Department for Communities and Local Government).

Leisure Industries Research Centre (2003), Sports volunteering in England in 2002 (London: Sport England)

Long J., et al., (2002) Count me in: the dimensions of social inclusion through culture and sport. LMU. Leeds UK

Lynn, P., \& Davis-Smith, J. (1992) The 1991 National Survey of Voluntary Activity in the UK (Berkhamstead: The Volunteer Centre UK). 
Misener, L., \& Mason, D. S. (2006) Creating community networks: can sporting events offer meaningful sources of social capital? Managing Leisure, 11, 39-56.

Munton, T., \& Zurawan, A. (2003) Active Communities: Headline Findings from the 2003 Home Office Citizenship Survey.

National Centre for Social Research (2000) Political Interest and Engagement in Young People (York: Joseph Rowntree Foundation).

Policy Action Team 10 (1999) Arts and Sport: A report to the Social Exclusion Unit (London: DCMS)

Portes, A. and Landolt, P. (1996) The Downside of Social Capital The American Prospect, 26, 18-21.

Putnam, R. D. (1993) The Prosperous Community: social capital and public life, The American Prospect, 4, 11- 18.

Putnam, R. D. (1995) Bowling Alone: Americas declining social capital, Journal of Democracy, 6, $65-78$.

Putnam, R. D. (2000) Bowling Alone: The collapse and revival of American Community (New York: Simon and Schuster/Touchstone).

Rojek, C. (2000) Leisure and Culture (Basingstoke, Macmillan).

Russell, I. (2005) A national framework for youth action and engagement. Russell Commission (London: Home Office)

Social Exclusion Unit (1998) Bringing Britain Together: A National Strategy for Neighbourhood Renewal (London: HM Cabinet Office Social Exclusion Unit).

Whiting, E., \& Harper, R. (2003) Young people and social capital, Office for National Statistics (London) 


\section{Table 1}

The impact of the Community Volunteers placements on respondents

It has increased my leadership skills

Respondents

It has increased my confidence

$87.5 \%$

It has improved my communication skills

$85 \%$

It has improved my organisational skills

$80 \%$

It made me think more about other roles in sport

$65 \%$

It made me want to do volunteer work with children/young people

$60 \%$

It has made me think more about different groups

$49.4 \%$

$48.8 \%$

It has made me want to do paid work in sports

$46.3 \%$

It has made me want to do volunteering in sports

$35.6 \%$

It has made me want to do other sports leadership/volunteering awards

$35.0 \%$

It has made me want to go to University

$28.1 \%$

I think more about health and fitness than before

$25.6 \%$

It has made me think more about the community where I live

$16.9 \%$

It has helped me to better understand other subjects at school/college

$16.3 \%$

It has made me want to do volunteering in areas other than sports

$16.3 \%$ 